\author{
О.Ф. Кривнова $*$, , С. В. Князев *,*, , О.С. Смирнова $* 3$ \\ *Московский государственный университет им. М. В. Ломоносова \\ **Национальный исследовательский университет «Высшая школа экономики» \\ (Россия, Москва) \\ okrivnova@mail.ru',svknia@gmail.com²,kisaolga@mail.ru
}

\title{
ИНТОНАЦИОННОЕ ЧЛЕНЕНИЕ И СЕГМЕНТИРУЮШАЯ СИЛА СЛОВОРАЗДЕЛОВ В ЗВУЧАЩЕМ ТЕКСТЕ (ДАННЫЕ ПЕРЦЕПТИВНОГО ЭКСПЕРИМЕНТА)*
}

В статье рассматривается проблема интонационного членения устной речи, дается краткое описание истории вопроса, уточняются базовые термины, поясняются понятия просодического шва и сегментирующей силы словораздела. Показана роль отечественных лингвистов и текстологов в открытии этого фонетического явления и в понимании его иерархической и функциональной природы. Приводятся примеры просодической разметки фрагментов устных русских текстов, которые имеются в трудах Л. В. Щербы и Р.И. Аванесова. Экспериментальное исследование, которое описывается в настоящей работе, имеет двоякую цель: во-первых, проверить гипотезу об иерархической природе просодического членения и ее отображении в глубине просодических швов; во-вторых, обосновать устойчивость и адекватность различения пяти градаций сегментирующей силы словоразделов как средства количественной оценки глубины просодического членения в звучащем тексте. Дизайн перцептивного эксперимента разрабатывался в предположении, что результаты аудирования будут наиболее согласованными в том случае, когда число различаемых уровней членения в оценочной шкале наиболее точно соответствует надежному восприятию глубины просодических границ участниками эксперимента. В итоге статистически достоверно показано, что аудиторы надежно и согласованно различают не более 5 уровней глубины просодических швов, поэтому в дальнейших исследованиях не имеет смысла использовать более детальные оценочные шкалы. Этот вывод подтверждается и результатами экспериментов по оценке сегментирующей силы словоразделов на материале других языков (английского и нидерландского). Можно предположить, что максимальная 5-уровневая шкала отражает универсальные свойства перцептивных ощущений человека в анализируемом фонетическом

\footnotetext{
* Исследование проведено при поддержке гранта РФФИ 15-06-06103.
} 
пространстве. Для многих практических задач достаточно учитывать этот результат и на начальной стадии технологических разработок в области синтеза и распознавания речи даже использовать более крупную 3-уровневую шкалу. В заключительной части статьи приводятся результаты произведенного анализа полученных данных в статистическом пакете STATISTICA: численные характеристики зависимостей между глубиной просодических швов, длительностью пауз на словоразделе, знаками препинания, элементами синтаксической разметки.

Ключевые слова: устная речь, просодическое членение, просодический шов, сегментирующая сила словораздела, восприятие, статистический анализ данных

Слово, как известно, является основной рабочей единицей как при порождении, так и при восприятии любого текста - и письменного, и устного. При этом каждая граница между словами (словораздел) имеет определенный сегментирующий потенциил, который может реализоваться с разной вероятностью и с разной силой в зависимости от типа текста, контекстных условий и различных контролирующих факторов локальной и глобальной природы. Носитель языка, даже не имеющий специального лингвистического образования, согласится с тем, что в линейной последовательности слов в тексте соседние слова в разной степени связаны между собой по смыслу, синтаксически и даже фонетически. Этот факт можно интерпретировать как признание разной сегментирующей силы (глубины) словоразделов. В письменном тексте в качестве формальных показателей сегментирующей силы словоразделов (word boundary strength) выступают знаки препинания: их наличие / отсутствие и тип. Знаки препинания не только членят текст на когерентные фрагменты, но и указывают в определенной степени на их относительный иерархический статус. В устной речи аналогичную функцию выполняют просодические средства: паузы, переломы тона и другие фонетические явления на граничных участках соседних слов в последовательности. Фонетическое членение звучащего текста с помощью просодических средств осуществляется говорящим в соответствии с общими принципами фонетической организации речи и с учетом смысловой и синтаксической структуры текста. В русскоязычной литературе для обозначения данного явления используется термин «просодическое членение» (далее ПЧ), а также, в качестве синонимов, синтагматическое и интонационное членение. В англоязычной литературе прочно закрепился термин “prosodic phrasing”, которым мы также будем пользоваться. Просодически маркированные словоразделы между фразовыми просодическими (супрасегментными) составляющими образуют просодические швы (разрывы) в звучащем тексте, что хорошо отражает англоязычный термин “prosodic break". Естественно предположить, что внутренняя иерархия ПЧ на фразовом уровне находит отражение в разной глубине («силе») просодических швов (далее ПШ), которая создается использованием разных просодических средств между и на краях просодических составляющих. Согласно имеющимся данным, самым сильным маркером является физическая пауза. В интонационной фонологии многие исследователи разделяют точку зрения, согласно которой иерархический статус просодической составляющей однозначно 
соответствует глубине ПШ, завершающего эту составляющую. Это положение так называемой строгой поуровневой гипотезы (Strict Layered Hypothesis, SLH) разделяется, однако, не всеми интонологами, но, к сожалению, никогда не проверялось экспериментально на сколько-нибудь представительном речевом материале, см. об этом [Ladd 1986; Ladd, Campbell 1991; Sanderman 1996; Selkirk 1984].

В отечественной лингвистике впервые обратил внимание на ПЧ и его особую природу академик Л.В. Щерба. Он писал: «В европейских языках (а вероятно и во многих других) самым могучим средством выражения связи между словами и группами слов является “интонация”, “фразировка” в самом широком смысле слова» [Щерба 1915]. Щерба обозначил практически все отличительные особенности этого явления, которые в настоящее время являются предметом исследования во многих работах по фразовой просодии, однако не описаны и не объяснены полностью ни для одного из европейских языков. Это относится, в частности, и к иерархической природе ПЧ. Щерба об этом писал так: «...синтагмы (минимальные единицы ИЧ) могут объединяться в группы высшего порядка с разными интонациями и, в конце концов, образуют фразу - законченное целое, которое может состоять из группы синтагм, но может состоять и из одной синтагмы, и которое нормально характеризуется конечным понижением тона» [Щерба 1955]. В этой же работе приведены авторские транскрипции русского стиха, наряду с французскими примерами, где используются 4 маркера для фразовых ПШ разной глубины: в завершении фоносинтагм ], полуфраз \{, фраз |, сверхфразовых единств ||. Поскольку словоразделы, не маркированные как ПШ, в транскрипциях Л. В. Щербы никак специально не помечены, можно считать, что в приводимых им примерах для обозначения сегментирующей силы словоразделов использовалась пятибалльная количественная шкала: $0,1,2,3,4$.

Много текстовых примеров с разметкой ПШ содержится и в книге Р.И. Аванесова «Русское литературное произношение» [Аванесов 1972]. Аванесов использует пять особых маркеров, фиксирующих разную глубину ПЧ : -, |, /, //, /// в направлении возрастания плюс чистый пробел, т. е. фактически исходит из шестибалльной количественной шкалы.

О.Ф. Кривнова [Кривнова 1995] описывает 4-балльную шкалу1 глубины ПШ, которые соответствуют просодическим составляющим, бо́льшим, чем фонетическое слово, следующим образом: просодическая/ фонетическая синтагма $<1>$; интонационная фраза $<2>$; интонационно-смысловой комплекс $<3>$; высказывание $<4>$.

В отличие от интроспективных транскрипций Л.В. Щербы и Р.И. Аванесова, в [Кривнова 1995] разметка ПШ в звучащем тексте производилась в рамках перцептивного эксперимента наивными носителями русского языка (10 человек). При этом было обнаружено, что при использовании пятибалльной шкалы глубины ПШ (или, иначе, сегментирующей силы словоразделов) испытуемые достаточно согласованно осуществляют разметку просодического членения текста.

${ }^{1}$ Фактически шкала была пятибалльная, так как словораздел без ПШ (нулевой) никак специально не маркировался. 
Результаты перцептивных экспериментов по оценке сегментирующей силы словоразделов на материале разных языков (английского, нидерландского и русского) свидетельствуют о поведенческой устойчивости оценок, полученных с использованием количественной шкалы, различающей не более 5 уровней глубины членения. Это позволяет предположить, что данная шкала отражает какие-то универсальные свойства перцептивных ощущений человека в соответствующем фонетическом пространстве. Для многих практических задач достаточно учитывать этот результат и даже сознательно использовать более крупную 3-уровневую шкалу, как это советует делать А. Сандерман [Sanderman 1996] на начальной стадии технологических разработок в области синтеза и распознавания речи. Однако для подтверждения указанной гипотезы с общефонетических научных позиций необходимо увеличить как количество и разнообразие рассматриваемых языков, так и число испытуемых, привлекаемых к ее верификации.

В будущих исследованиях важно также учитывать некоторые методические нюансы. Прежде всего, возникает вопрос о речевом материале, на базе которого проводится исследование глубины ПШ и иерархии ПЧ в целом. В [Кривнова 1995] эксперимент проводился на материале естественного связного русского текста с достаточно сложным и разнообразным синтаксисом, который был озвучен непрофессиональным диктором. В экспериментах А. Сандерман использовался список предложений, озвученных отдельно или в небольшом контексте как профессиональным, так и непрофессиональными дикторами. Синтаксис этих предложений контролировался экспериментатором, причем могли использоваться и специально сконструированные «искусственные» примеры. В экспериментах с использованием ТoBI-разметки [Silverman et al. 1992] на материале английского языка преобладают небольшие новостные тексты, озвученные профессиональными дикторами или радиоведущими. Каждый тип материала имеет свои преимущества и сложности, которые мы не можем здесь обсуждать, однако очевидно, что выбор того или иного материала требует экспликации и обоснования. Есть различия и в процедуре проведения перцептивного эксперимента. Так, в зарубежных работах предполагается оценка сегментирующей силы каждого словораздела в тексте, причем в экспериментах Сандерман испытуемые (носители языка) давали оценки исключительно на основе своих перцептивных ощущений при многократном прослушивании материала, в то время как в ТоBIэкспериментах оценки брейковых показателей были получены от экспертов, которым разрешалось использовать не только собственные перцептивные ощущения, но и сопутствующие акустические данные. Эксперимент в [Кривнова 1995] основывался только на перцептивных ощущениях, возникающих в реальном времени, а двухэтапная процедура получения перцептивных оценок, не предполагавшая оценку глубины членения для каждого словораздела, значительно облегчала, на наш взгляд, задачу испытуемых, повышая адекватность их окончательных оценок. В целом, в исследованиях ПЧ требуется обсуждение возможных процедурных стратегий и поиск оптимального дизайна эксперимента для каждой конкретной задачи. 
Экспериментальное исследование, положенное в основу настоящей работы, имело двоякую цель: во-первых, проверить экспериментально идеи, связанные с иерархической природой ПЧ и ее отображением в глубине ПШ; во-вторых, обосновать с использованием перцептивных и статистических методов устойчивость и адекватность пятибалльной шкалы уровней (градаций) сегментирующей силы словоразделов как средства количественной оценки глубины ПШ в русском прозаическом тексте.

Эксперимент по восприятию наличия и типа фонетических/просодических границ в связном тексте состоял из двух этапов и проводился в режиме удаленного доступа. На каждом из этапов материалом служил звучащий текст, представлявший собой фрагмент повести И. Грековой «Кафедра», озвученный профессиональным фонетистом. На первом этапе объем текста составлял 470 слов.

Информанты-аудиторы (19 человек в возрасте от 18 до 53 лет, 4 мужчины, 15 женщин, носители современного русского литературного языка) получили задание прослушать звучащий текст (в домашних условиях) и в тех местах, где ими ощущались какие-либо просодические границы, проставить в соответствующем графическом пробеле текста, напечатанном без знаков препинания и заглавных букв (см. Приложение 1), цифровой показатель от 1 до 7 в соответствии со степенью выраженности границы (1 - минимальная выраженность границы, 7 - максимальная). Общее время прослушивания, размер прослушиваемых фрагментов и количество прослушиваний каждого никак не регламентировалось. Следует отметить, что 7-балльная шкала была выбрана как стартовая, с запасом, с учетом того, что на следующем этапе эксперимента число надежно и согласованно распознаваемых уровней ПШ может быть уменьшено.

Результаты эксперимента приведены в табл. ниже (0 соответствует отсутствию выделения границы информантом). Заливкой помечены столбцы с разметкой участников, показавших наименее согласованные результаты. В столбце ПШ дана итоговая разметка по наиболее согласованной группе из семи участников.

На втором этапе эксперимента объем аудиоматериала составлял около 2700 слов. Предоставленная информантам аудиозапись в местах словоразделов была разделена на относительно равные части таким образом, что каждому аудиофрагменту соответствовали примерно две строки печатного текста (от 100 до 190 печатных знаков). При этом последняя строка предшествующего фрагмента повторялась в начале следующего, для того чтобы информанты могли оценить наличие и тип просодической границы в местах разделения текста на фрагменты. Таким образом, первый аудиофрагмент состоял из первой и второй строк текста, второй из второй и третьей, третий - из третьей и четвертой и т. д. (см. Приложение 2).

Обработка результатов первого эксперимента показала, что его участники надежно и согласованно оценивают только 5 уровней ПШ, поэтому на втором этапе эксперимента шкала оцениваемых уровней была сокращена до пяти градаций.

Дизайн эксперимента разрабатывался в предположении, что при использовании шкалы ПШ, которая наиболее точно соответствует надежно воспринимаемому числу градаций глубины ПШ, результаты аудирования будут наиболее согласованными. 
Фрагмент итогового протокола оценок информантов по эксперименту 1

\begin{tabular}{|c|c|c|c|c|c|c|c|c|c|c|c|c|c|c|c|c|c|c|c|c|}
\hline \multirow{2}{*}{ Текст } & \multicolumn{19}{|c|}{ Аудиторы } & \multirow{2}{*}{ ПШ } \\
\hline & I & II & III & IV & V & VI & VII & VIII & IX & $x$ & XI & XII & XIII & XIV & $\mathbf{X V}$ & $\mathrm{XVI}$ & XVII & XVIII & XIX & \\
\hline Люда & 2 & 0 & 0 & 0 & 0 & 0 & 0 & 0 & 0 & 0 & 0 & 0 & 0 & 1 & 1 & 0 & 0 & 0 & 0 & 0 \\
\hline Величко & 3 & 2 & 2 & 1 & 5 & 0 & 2 & 3 & 4 & 1 & 2 & 1 & 3 & 3 & 3 & 2 & 1 & 0 & 1 & 2 \\
\hline родилась & 2 & 3 & 0 & 0 & 0 & 0 & 0 & 0 & 0 & 0 & 0 & 0 & 0 & 1 & 1 & 0 & 0 & 0 & 0 & 0 \\
\hline и & 1 & 0 & 0 & 0 & 0 & 0 & 0 & 0 & 0 & 0 & 0 & 0 & 0 & 1 & 1 & 0 & 0 & 0 & 0 & 0 \\
\hline росла & 2 & 0 & 0 & 0 & 0 & 0 & 0 & 0 & 0 & 0 & 0 & 0 & 0 & 1 & 2 & 0 & 0 & 0 & 0 & 0 \\
\hline B & 1 & 0 & 0 & 0 & 0 & 0 & 0 & 0 & 0 & 0 & 0 & 0 & 0 & 1 & 1 & 0 & 0 & 0 & 0 & 0 \\
\hline провинции, & 2 & 3 & 3 & 2 & 4 & 1 & 3 & 3 & 5 & 2 & 2 & 2 & 4 & 3 & 4 & 2 & 4 & 2 & 3 & 2 \\
\hline B & 0 & 0 & 0 & 0 & 0 & 0 & 0 & 0 & 0 & 0 & 0 & 0 & 0 & 1 & 1 & 0 & 0 & 0 & 0 & 0 \\
\hline одном & 2 & 0 & 0 & 0 & 0 & 0 & 0 & 0 & 0 & 0 & 0 & 0 & 0 & 1 & 1 & 0 & 0 & 0 & 0 & 0 \\
\hline из & 1 & 0 & 0 & 0 & 0 & 0 & 0 & 0 & 0 & 0 & 0 & 0 & 0 & 1 & 1 & 0 & 0 & 0 & 0 & 0 \\
\hline среднерусских & 2 & 4 & 2 & 1 & 2 & 0 & 3 & 2 & 3 & 1 & 2 & 1 & 2 & 4 & 4 & 1 & 3 & 1 & 1 & 2 \\
\hline неперспективных & 2 & 0 & 1 & 0 & 0 & 0 & 0 & 0 & 1 & 0 & 0 & 0 & 0 & 2 & 4 & 0 & 0 & 0 & 1 & 0 \\
\hline городков. & 4 & 7 & 4 & 3 & 7 & 2 & 6 & 4 & 7 & 3 & 4 & 3 & 6 & 7 & 6 & 5 & 6 & 5 & 7 & 3 \\
\hline
\end{tabular}

В отличие от экспериментов А. Сандерман мы не производили искусственного укрупнения 7-балльной шкалы. «Лишние» уровни просто не вошли в итоговую разметку — в результате обработки данных, полученных на первом этапе эксперимента, укрупнение шкалы произошло автоматически. Уровень согласия отобранной группы участников 2-го этапа эксперимента немного ниже, чем для первого. Это объясняется тем, что группа информантов, участвовавших во втором этапе эксперимента, была меньше и имела другой состав, в результате чего отбор был менее строгим.

Информанты (11 человек в возрасте от 18 до 55 лет, 2 мужчин, 9 женщин, носители современного русского литературного языка) получили задание прослушать аудиофайлы (в любой программе для воспроизведения звука, желательно в тихом помещении, без отвлекающих обстоятельств), и в тех местах, где при прослушивании они воспринимали какие-либо границы, разрывы, нарушения плавности речи диктора, отсутствие фонетической слитности смежных слов, проставить в соответствующем пробеле (словоразделе предоставленного текстового файла) цифровой показатель от 1 до 5 в соответствии со степенью выраженности воспринимаемой границы (1 - минимальная выраженность границы, 5 - максимальная).

С целью стандартизации заполнения протоколов и минимизации доли ручного труда при их обработке была разработана электронная форма протокола, допускающая ввод только разрешенных значений шкалы и только в специальные поля на словоразделах. По умолчанию значение поля - пробел, при обработке воспринимаемый как «0». Первый столбец формы содержит номер аудиофрагмента — название прослушиваемого файла. В Приложении 2 дан пример заполнения формы протокола.

Информанты были также проинструктированы прослушать несколько первых аудиофайлов, не размечая текст, чтобы привыкнуть к дизайну эксперимента, самому тексту и диктору. 
Каждый звуковой файл было разрешено прослушивать не более трех раз, после очередного повторного прослушивания разрешалось исправлять первоначально проставленные цифровые показатели. Информантам было предложено выполнять задание в один сеанс, а при отсутствии такой возможности в разное время, но в течение 1-2 дней подряд.

Заполненные протоколы перцептивного эксперимента после прослушивания всех аудиоматериалов с указанием персональных данных информанта, количества сеансов прослушивания и времени разрывов между ними отправлялись организаторам по электронной почте.

Результаты второго этапа эксперимента фиксировались в таблицах — образец такой таблицы приведен в Приложении 3 (цифра 0 соответствует отсутствию обозначения границы информантом). Для получения итоговой разметки ПШ использовался тот же метод поэтапного выделения согласованной группы информантов, что и на первом этапе эксперимента, описанного выше. Суть его кратко изложена ниже.

В теории и практике экспертных оценок согласующее решение для группы экспертов часто получается как наименее уклоняющееся в смысле некоторой меры расстояния (медиана Кемени) от мнений всех участников группы. В нашем случае логично было бы рассматривать разметки ПШ как «упорядоченные классификации», однако алгоритмы вычисления согласующей разметки в этом случае достаточно сложны и плохо применимы к разметке длинного текста. Мы рассматривали разметки ПШ просто как вектора с ограниченным набором упорядоченных значений координат и использовали линейную меру расстояния между ними, так называемое «расстояние городских кварталов». Согласующее решение при этом вычисляется как покоординатная медиана. В случае нечетного числа согласуемых разметок она состоит из тех же элементов, устойчива к выбросам, легко вычисляется: если оценка силы словораздела принимается абсолютным большинством голосов, медиана совпадает с результатом голосования.

Первичный анализ данных первого этапа эксперимента показал не только очень плохую согласованность разметок отдельных информантов, но и наличие «аномалов», которые либо помечают ПШ почти на каждом словоразделе, либо не слышат их почти никогда. Поэтому была предложена следующая простая пошаговая процедура согласования. На каждом шаге для текущей группы информантов вычисляется согласующая разметка. Информант, разметка которого лежит на наибольшем расстоянии от нее, удаляется из группы. Разброс результатов быстро стабилизируется, в результате чего удалось выделить группы из 5 (наиболее единодушная), 7 и 9 человек, показывающие удовлетворительный уровень согласованности, итоговые разметки по которым весьма близки. Эти разметки не содержат пометок уровня «7», а уровень «6» всего 2 раза отмечается в итоговых разметках некоторых групп только при сбоях - особо длинных неречевых паузах, возникающих при переворачивании страниц или оговорках.

Выделение полученных согласованных групп подтверждается также формальной классификацией разметок, что позволяет получить согласующую итоговую разметку как центроид «более плотного» класса, с меньшим расстоянием 
от центроида. Такая разметка близка к полученной с помощью пошаговой процедуры.

Следует отметить, что итоговая разметка начального фрагмента текста в 470 слов, полученная на втором этапе, при другом дизайне эксперимента и другой шкале, также почти полностью совпадает с разметкой, полученной на первом этапе (пошаговая процедура и центроид). Благодаря продуманной процедуре разметки и более адекватной оценочной шкале уменышается элемент угадывания и улучшается исходный уровень согласия группы.

В итоге можно сказать, что проведенный эксперимент статистически достоверно показал, что информанты надежно и согласованно различают не более 5 уровней глубины просодических швов, поэтому в дальнейших исследованиях не имеет смысла использовать более детальные оценочные шкалы. Этот вывод подтверждается и результатами экспериментов по оценке сегментирующей силы словоразделов на материале других языков (английского и нидерландского). Можно предположить, что максимальная 5-уровневая шкала отражает универсальные свойства перцептивных ощущений человека в анализируемом фонетическом пространстве. Для многих практических задач достаточно учитывать этот результат и на начальной стадии технологических разработок в области синтеза и распознавания речи даже использовать более крупную трехуровневую шкалу.

Итоговая разметка ПШ была включена в сводную базу данных различных текстовых признаков словоразделов, как фонетических, так и нефонетических. Анализ этих данных в статистическом пакете STATISTICA позволил вычислить численные характеристики (симметричные и асимметричные коэффициенты связи в таблицах сопряженных признаков) зависимостей между глубиной ПШ, длительностью пауз, знаками препинания, элементами синтаксической разметки. Получены диапазоны пауз (доверительные интервалы с вероятностью накрытия порядка более 80\%), близкие к диапазонам, полученным ранее в экспериментах О.Ф. Кривновой [Кривнова 1995], и наиболее вероятные значения длительности пауз, соответствующие различным уровням глубины ПШ. А именно: 104-450 мс с вероятностью попадания 93\% и наиболее вероятным значением около 400 мс для ПШ 2, 450-1150 мс (82\%, 800 мс) для ПШ 3, больше 1150 (83\%, 1200 мс) для ПШ 4 (по данным первого этапа эксперимента).

Классификация длительностей пауз методом К-средних с увеличивающимся количеством классов (наилучшие результаты классификации наблюдаются при пятишести классах) позволяет получить аналогичные диапазоны и «типичные» значения для длительностей, соответствующих «сильному» $(3,4,5)$ уровню ПШ или его отсутствию - устойчивые четкие классы со следующими центроидами: 0, 800, 1200, 2000 мс, которые почти не меняются при увеличении числа классов. «Слабые» уровни $(1,2)$ часто бывают беспаузальными и хуже классифицируются по этому признаку, однако наблюдаются и классы с центроидами порядка 100-200, 400 мс.

Выявлено также неплохое соответствие рангового распределения ПШ закону Ципфа-Мандельброта, что говорит о «естественности» полученной разметки. Подробно результаты обработки проведенного перцептивного эксперимента изложены в работе [Смирнова 2017]. 


\title{
Литература
}

Аванесов Р. И. Русское литературное произношение. М.: Просвещение, 1972.415 с.

Кривнова О.Ф. Перцептивная и смысловая значимость просодических швов в связном тексте // Проблемы фонетики. Вып. 2. М.: Наука, 1995. С. 229-238.

Смирнова О.С. Статистический анализ результатов перцептивного оценивания глубины просодических швов в русском звучащем тексте // Компьютерная лингвистика и интеллектуальные технологии: по материалам международной конференции «Диалог 2017». М., 2017. [Электронный ресурс]. Электрон. дан. Режим доступа: www.dialog-21.ru/media/3980/smirnovaos.pdf (свободный). Загл. с экрана.

Щерба Л. В. Восточнолужицкое наречие. Пг., 1915. 194 с.

Щерба Л. В. Фонетика французского языка. М.: Изд-во лит-ры на иностранных языках, 1955. $304 \mathrm{c}$.

Ladd R. Prosodic phrasing: a case of recursive prosodic structure // Phonology Yearbook. 1986. No. 3. P. 311-340.

Ladd B., Campbell D.R. Theories of prosodic structure: evidence from syllable duration // Proc. of the $12^{\text {th }}$ Congress of Phonetic Sciences. Aix-en-Provance, 1991. P. 290-293.

Sanderman A. Prosodic Phrasing (production, perception, acceptability and comprehension). Eindhoven, 1996. 129 p.

Selkirk E. Phonology and syntax: the relation between sound and structure. Cambridge, Massachusetts: The MIT Press, 1984. 476 p.

Silverman K., Beckman M., Pitrelli J., Ostendorf M., Wightman C., Price P., Pierrehumbert J., Hirshberg J. ToBI: A standart for labelling English prosody // Proc. of the 1992 International Conference on Spoken Language Processing (ICSLP). 1994. P. 867-870.

\author{
Olga F. Krivnova*, , Sergey V. Knyazev ${ }^{*} * *, 2$, Olga S. Smirnova ${ }^{*, 3}$ \\ *Lomonosov Moscow State University \\ **National Research University Higher School of Economics \\ (Russia, Moscow) \\ okrivnova@mail.rul,svknia@gmail.com²,kisaolga@mail.ru
}

\section{PROSODIC PHRASING AND WORDBREAKS' STRENGTH IN THE SPOKEN TEXT (DATA OF PERCEPTION EXPERIMENT)}

The paper discusses the problem of oral speech prosodic phrasing, gives a brief description of the history of the issue, clarifies the basic terms, explains the concept of prosodic break and word boundary strength. The role of Russian linguists and textologists in the discovery of this phonetic phenomenon and in understanding its hierarchical and functional nature is shown. Examples of prosodic labeling of spoken Russian texts are given, which are available in the works by L. V. Shcherba and R. I. Avanesov. The experimental study is described in this paper has a twofold purpose: 1 . To test the 
hypothesis about the hierarchical nature of prosodic phrasing and its mapping in the prosodic breaks' depth; 2 . To substantiate the adequacy of distinguishing 5 levels of the wordbreak' strength as a means of quantifying the prosodic breaks depth in the spoken text. The experiment design was developed under the assumption that perception would be most consistent when the number of distinct levels of prosodic breaks in the evaluation scale would be most closely correspond to the reliable perception of the listeners. As a result, it was shown statistically reliable that listeners consistently distinguish no more than 5 levels of break's strength. So it makes no sense to use more detailed evaluation scales in further studies. This conclusion is confirmed by the results of appraisal perception experiments on the material of other languages (English and Dutch). It can be assumed that the maximum 5-level scale reflects the universal properties of human perceptual sensations in the analyzed phonetic space. The final part of the paper presents the results of the obtained data analysis in the statistical package STATISTICA: numerical characteristics of dependencies between the prosodic breaks' depth, pauses duration on the word boundaries, punctuation marks, elements of syntactic labeling.

Key words: Spoken language, prosodic phrasing, prosodic break' depth, word boundary strength, perception, statistical data analysis

\section{References}

Avanesov R. I. Russkoe literaturnoe proiznoshenie [Russian Literary Pronunciation]. Moscow, Prosveshchenie Publ., 1972. 415 p.

Krivnova O.F. [Perception and semantic relevance of prosodic breaks in spoken text]. Problemy Fonetiki. Moscow, Nauka Publ., 1995. Iss. 2. P. 229-238. (In Russ.)

Ladd R. Prosodic phrasing: a case of recursive prosodic structure. Phonology Yearbook. 1986. No. 3. P. 311-340.

Ladd B., Campbell D. R. Theories of prosodic structure: evidence from syllable duration. Proc. of the $12^{\text {th }}$ Congress of Phonetic Sciences. Aix-en-Provance, 1991. P. 290 293.

Sanderman A. Prosodic Phrasing (production, perception, acceptability and comprehension). Eindhoven, 1996. 129 p.

Selkirk E. Phonology and syntax: the relation between sound and structure. Cambridge, Massachusetts: The MIT Press, 1984. $476 \mathrm{p}$.

Silverman K., Beckman M., Pitrelli J., Ostendorf M., Wightman C., Price P., Pierrehumbert J., Hirshberg J. ToBI: A standart for labelling English prosody. Proc. of the 1992 International Conference on Spoken Language Processing (ICSLP). 1994. P. 867-870.

Smirnova O. S. [Statistical analysis of the results of prosodic breaks' perceptual evaluation in spoken Russian text]. Availiable at: www.dialog-21.ru/media/3980/smirnovaos. pdf (date of accesse 31.05.2017).

Shcherba L. V. Vostochnoluzhitskoje narechie [Eastern European dialect]. Petrograd, 1915. 194 p.

Shcherba L.V. Phonetika frantsuzskogo jazyka [Phonetics of the French language]. Moscow, Izdatel'stvo literatury na inostrannykh yazykakh Publ. 1955. 304 p. 


\section{Приложение 1 \\ Фрагмент отрывка из текста И. Грековой «Кафедра», использованный в перцептивном эксперименте}

люда величко родилась и росла в провинции в одном из среднерусских неперспективных городков одна фабрика лесопильный завод вязальная мастерская комбинат бытового обслуживания в так называемом центре несколько каменных зданий полуразрушенная церковь со срезанным куполом превращенная как водится в склад вокруг нее кладбище с железными крестами и бумажными розами...

\section{Приложение 2}

Фрагмент протокола перцептивного эксперимента по восприятию наличия и типа просодических границ в связном тексте

Персональные данные информанта. Все данные вводятся в поля формы.

Количество сеансов прослушивания 1

Интервалы между сеансами (форма заполнения произвольная)

\begin{tabular}{|c|c|}
\hline 001 & 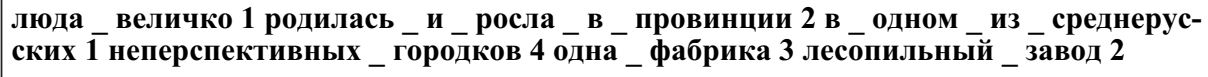 \\
\hline 002 & 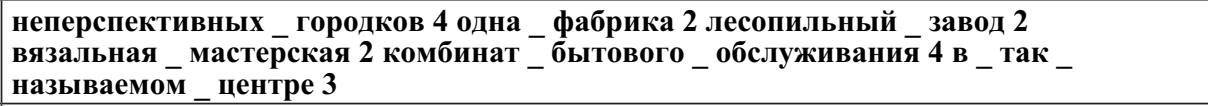 \\
\hline 003 & $\begin{array}{l}\text { вязальная_- мастерская } 3 \text { комбинат_бытового_обслуживания } 4 \text { в _ так _- } \\
\text { называемом_центре } 3 \text { несколько_каменных _ зданий } 4 \text { полуразрушенная _- } \\
\text { церковь_co_cрезанным _ куполом } 2\end{array}$ \\
\hline 004 & $\begin{array}{l}\text { несколько _ каменных _ зданий } 4 \text { полуразрушенная_церковь } 1 \text { со _ срезанным _ } \\
\text { куполом } 2 \\
\text { превращенная_как__одится__в_склад } 4 \text { вокруг_нее_кладбище } 3\end{array}$ \\
\hline 005 & превращенная _ как_водится _в _ склад 4 вокруг_ нее _ кладбище 3 \\
\hline 265 & угу 2 на _ вторник 4 \\
\hline 266 & $\begin{array}{l}\text { угу } 2 \text { на_вторник } 4 \\
\text { ладно } 2 \text { подготовимся } 3 \text { садись } 2 \text { пей _ чай } 5\end{array}$ \\
\hline
\end{tabular}

Номера фрагментов в первом столбце таблицы являются также именами соответствующих аудиофайлов. 


\section{Приложение 3}

Результаты перцептивного эксперимента и их обработки (фрагмент)

\begin{tabular}{|c|c|c|c|c|c|c|c|c|c|c|c|c|c|c|c|}
\hline \multirow{2}{*}{ Текст } & \multirow{2}{*}{$3 \Pi$} & \multirow{2}{*}{$3 \Pi+$} & \multirow{2}{*}{ Пауза } & \multicolumn{11}{|c|}{ АУДИТОРЫ } & \multirow{2}{*}{$\begin{array}{c}\text { ИTOГ } \\
\text { MED } \\
5 / 11\end{array}$} \\
\hline & & & & I & II & III & IV & $\mathbf{V}$ & VI & VII & VIII & IX & $\mathbf{X}$ & $\mathbf{X I}$ & \\
\hline Люда & & - & 0,0 & 0 & $\mathbf{0}$ & $\mathbf{0}$ & 0 & $\mathbf{0}$ & $\mathbf{0}$ & $\mathbf{0}$ & $\mathbf{0}$ & 0 & $\mathbf{0}$ & $\mathbf{0}$ & $\mathbf{0}$ \\
\hline Величко & & - & 128,0 & 2 & 2 & $\mathbf{0}$ & 4 & 1 & 3 & 1 & 1 & 1 & 3 & 3 & 1 \\
\hline родилась & & $=$ & 0,0 & $\mathbf{0}$ & $\mathbf{0}$ & $\mathbf{0}$ & $\mathbf{0}$ & $\mathbf{0}$ & $\mathbf{0}$ & $\mathbf{0}$ & $\mathbf{0}$ & $\mathbf{0}$ & $\mathbf{0}$ & $\mathbf{0}$ & $\mathbf{0}$ \\
\hline и & & _ & 0,0 & $\mathbf{0}$ & $\mathbf{0}$ & $\mathbf{0}$ & $\mathbf{0}$ & $\mathbf{0}$ & $\mathbf{0}$ & $\mathbf{0}$ & $\mathbf{0}$ & $\mathbf{0}$ & $\mathbf{0}$ & $\mathbf{0}$ & $\mathbf{0}$ \\
\hline росла & & _ & 0,0 & $\mathbf{0}$ & $\mathbf{0}$ & $\mathbf{0}$ & 0 & $\mathbf{0}$ & $\mathbf{0}$ & $\mathbf{0}$ & $\mathbf{0}$ & 0 & $\mathbf{0}$ & $\mathbf{0}$ & $\mathbf{0}$ \\
\hline B & & - & 0,0 & $\mathbf{0}$ & $\mathbf{0}$ & $\mathbf{0}$ & $\mathbf{0}$ & $\mathbf{0}$ & $\mathbf{0}$ & $\mathbf{0}$ & $\mathbf{0}$ & 0 & $\mathbf{0}$ & $\mathbf{0}$ & $\mathbf{0}$ \\
\hline провинции, & , & 3IIT & 540,0 & 3 & 3 & 3 & 4 & 2 & 2 & 2 & 2 & 2 & 3 & 3 & 2 \\
\hline B & & - & 0,0 & $\mathbf{0}$ & $\mathbf{0}$ & $\mathbf{0}$ & $\mathbf{0}$ & $\mathbf{0}$ & $\mathbf{0}$ & $\mathbf{0}$ & $\mathbf{0}$ & $\mathbf{0}$ & $\mathbf{0}$ & $\mathbf{0}$ & $\mathbf{0}$ \\
\hline одном & & - & 0,0 & $\mathbf{0}$ & $\mathbf{0}$ & $\mathbf{0}$ & $\mathbf{0}$ & $\mathbf{0}$ & $\mathbf{0}$ & $\mathbf{0}$ & $\mathbf{0}$ & $\mathbf{0}$ & $\mathbf{0}$ & $\mathbf{0}$ & $\mathbf{0}$ \\
\hline из & & - & 0,0 & $\mathbf{0}$ & $\mathbf{0}$ & $\mathbf{0}$ & $\mathbf{0}$ & $\mathbf{0}$ & $\mathbf{0}$ & $\mathbf{0}$ & $\mathbf{0}$ & $\mathbf{0}$ & $\mathbf{0}$ & $\mathbf{0}$ & $\mathbf{0}$ \\
\hline среднерусских & & & 0,0 & 1 & 1 & 2 & 2 & 2 & $\mathbf{0}$ & 1 & 1 & 1 & 1 & 3 & 1 \\
\hline неперспективных & & & 0,0 & $\mathbf{0}$ & $\mathbf{0}$ & $\mathbf{0}$ & $\mathbf{0}$ & $\mathbf{0}$ & $\mathbf{0}$ & $\mathbf{0}$ & $\mathbf{0}$ & $\mathbf{0}$ & $\mathbf{0}$ & $\mathbf{0}$ & $\mathbf{0}$ \\
\hline городков. & . & ТЧК & 1114,0 & 4 & 3 & 4 & 5 & 4 & 3 & 5 & 4 & 3 & 5 & 4 & 4 \\
\hline Одна & & & 0,0 & $\mathbf{0}$ & $\mathbf{0}$ & $\mathbf{0}$ & $\mathbf{0}$ & $\mathbf{0}$ & $\mathbf{0}$ & $\mathbf{0}$ & $\mathbf{0}$ & $\mathbf{0}$ & $\mathbf{0}$ & $\mathbf{0}$ & $\mathbf{0}$ \\
\hline фабрика, & , & 3IIT & 353,0 & 2 & 2 & $\mathbf{0}$ & 4 & 2 & 2 & 3 & 2 & 2 & 3 & 3 & 2 \\
\hline лесопильный & & & 0,0 & $\mathbf{0}$ & $\mathbf{0}$ & $\mathbf{0}$ & $\mathbf{0}$ & $\mathbf{0}$ & $\mathbf{0}$ & $\mathbf{0}$ & $\mathbf{0}$ & $\mathbf{0}$ & $\mathbf{0}$ & $\mathbf{0}$ & $\mathbf{0}$ \\
\hline завод, & , & 3 3IT & 358,0 & 2 & 3 & 0 & 4 & 2 & 2 & 2 & 2 & 0 & 3 & 3 & 2 \\
\hline вязальная & & & 0,0 & $\mathbf{0}$ & $\mathbf{0}$ & $\mathbf{0}$ & $\mathbf{0}$ & $\mathbf{0}$ & $\mathbf{0}$ & $\mathbf{0}$ & $\mathbf{0}$ & $\mathbf{0}$ & $\mathbf{0}$ & $\mathbf{0}$ & $\mathbf{0}$ \\
\hline мастерская, & , & $3 I I T$ & 839,0 & 3 & 3 & 4 & 4 & 2 & 2 & 3 & 3 & 2 & 4 & 3 & 3 \\
\hline комбинат & & & 0,0 & $\mathbf{0}$ & $\mathbf{0}$ & $\mathbf{0}$ & 1 & $\mathbf{0}$ & $\mathbf{0}$ & $\mathbf{0}$ & $\mathbf{0}$ & 0 & $\mathbf{0}$ & $\mathbf{0}$ & $\mathbf{0}$ \\
\hline бытового & & & 0,0 & $\mathbf{0}$ & $\mathbf{0}$ & 0 & 1 & $\mathbf{0}$ & $\mathbf{0}$ & $\mathbf{0}$ & $\mathbf{0}$ & 0 & $\mathbf{0}$ & $\mathbf{0}$ & $\mathbf{0}$ \\
\hline обслуживания. & . & ТЧК & 913,0 & 4 & 5 & 4 & 5 & $\mathbf{0}$ & 5 & 5 & 4 & 4 & 5 & 4 & 4 \\
\hline
\end{tabular}

Итоговая разметка получена по данным разметок информантов II, V, VII, VIII, XI (столбцы без заливки). 